\title{
Construção e Validação de uma Escala de Comportamentos Mediacionais de Educadores Infantis
}

\author{
Escala Mediacional de Educadores Infantis
}

\author{
Celia Vectore \\ Vanessa Cristina Alvarenga \\ Sinésio Gomide Júnior
}

\section{Resumo}

O presente estudo objetivou a construção e validação de uma escala de avaliação de comportamentos mediacionais, observados na interação de educadores com crianças de creche. Foi realizada a análise de conteúdo dos 58 itens iniciais que compuseram a escala por cinco juízes para verificação do índice de concordância. Foram eliminados 21 itens e a escala passou a ser composta por 37 itens. Foi realizado um estudo piloto da escala por meio da observação dos comportamentos mediacionais de 315 educadores infantis de dez cidades, das regiões de Minas Gerais e São Paulo. A análise fatorial dos itens identificou quatro fatores denominados interação dos educadores nas atividades lúdicas; modos de transmissão de conteúdos para as crianças; recompensa ofertada às crianças; postura dos educadores frente às brincadeiras competitivas, os quais se relacionam à interação dos educadores nas atividades lúdicas que explicam $36 \%$ da variância da escala. Foram eliminados 16 itens cuja carga fatorial foi menor que 0,30, resultando em 23 itens. Palavras-Chave: Avaliação Psicológica; Psicometria; Mediação cognitiva

\section{Construction and validation of a mediational behavior scale of children educators}

\begin{abstract}
The objective of this paper was the construction and validation of a mediational behavior scale as observed in the interaction of educators of children in childcare facility (crèche). A content analysis of the first 58 items comprising the scale was carried out by five judges so as to verify concordance (agreement) rate. 21 items were eliminated, thus the scale was comprised of the remaining 37 items. A pilot study of the scale via mediational behavior observation of 315 children educators of cities in Minas Gerais and São Paulo was carried out. The factor analysis of the items identified four factors: interaction of the educators in recreational activities; modes of sharing content with children; children's rewards; educators' postures re; competitive games. These factors are connected to the educator's interaction in recreational activities which explain $36 \%$ of the scale variable. 16 items whose factorial weight was below 0,30 were disconsidered, thus remaining 23 items. Keyword: Psychological assessment; Psychometrics; Cognitive mediation.
\end{abstract}

\section{Construcción y validación de una escala de comportamientos mediadotes de educadores infantiles}

\section{Resumen}

El estudio ha tenido como objetivo la construcción y validación de una escala de evaluación de comportamientos mediadotes observados en la interacción de educadores con niños de guardería. Ha sido realizado el análisis del contenido de los 58 ítems iniciales que han compuesto la escala por cinco jueces para verificar el índice de concordancia. Han sido eliminados 21 ítems y la escala ha pasado a ser formada por 37 ítems. Ha sido realizado un estudio piloto de la escala por medio de la observación de los comportamientos mediadotes de 315 educadores infantiles de diez ciudades de las regiones de Minas Gerais y São Paulo. El análisis factorial de los ítems ha identificado cuatro factores denominados interacción de los educadores en las actividades lúdicas; formas de transmisión de los contenidos para los niños; recompensa ofrecida a os niños; posición de los educadores frente a los juegos competitivos, los cuales están relacionados a la interacción de los educadores en las actividades lúdicas que han explicado $36 \%$ de la variancia de la escala. Han sido eliminados 16 ítems cuya carga factorial ha sido menor a 0,30, resultando en 23 ítems.

Palabras clave: Evaluación Psicológica, Psicometría; Mediación cognitiva. 


\section{Introdução}

A relação entre os comportamentos exibidos pelos educadores com o desempenho, a adequação ou adaptação do aprendiz ao contexto pré-escolar tem sido objeto de vários estudos tanto no Brasil quanto no exterior. Tais comportamentos podem ser explicitados por meio da identificação de ações voltadas à sensibilidade, ao empenho, ao envolvimento do educador às demandas das crianças sob sua responsabilidade (Vectore e Silva, 2004; OliveiraFormosinho, 200 I; Klein, 1996 a, b).

As duas últimas décadas do século $X X$ e o início do terceiro milênio têm testemunhado um expressivo realce dado à educação infantil, em virtude da crescente preocupação com a qualidade dos serviços prestados em uma fase do desenvolvimento humano, particularmente sensível às estimulações ambientais.

Estudos e pesquisas, como os de Malaguzzi (1994) e Gardner (1999) sobre a criança pequena e os cuidados a serem a ela dispensados têm contribuído para a instauração de uma nova organização social, cuja a ênfase se traduz na importância em se considerar a cultura da infância. Isso refere-se a tornar visível o fato de que a criança nas interações que vivencia, tem capacidade de construir de forma sistematizada, modos de significação e ação próprios (Sarmento, 2003) que, quando respeitados fomentam o seu desenvolvimento.

Tomando-se como parâmetro a possibilidade de otimização do desenvolvimento infantil, um dos fatores fortemente relacionado é o que considera a qualidade dos serviços prestados à infância. No Brasil, o recente relatório do Fundo das Nações Unidas para a Infância (UNICEF, 2005) enfatiza que a educação é um dos pilares para a ruptura do ciclo de pobreza e mostra que das 23,I milhões de crianças de 0 a 6 anos de idade, há ainda $38,6 \%$ de crianças na faixa etária de 4 a 6 anos que não são atendidas em instituições préescolares. Em relação à população de 0 a 3 anos, somente $11,7 \%$, freqüentam algum tipo de instituição infantil. Em termos numéricos, dados obtidos pelo Ministério da Educação (MEC, 2005) mostram que foram matriculadas em 2005, I.4I5.I3I crianças em creches e 5.789 .543 em pré-escolas.
Em acréscimo a tal situação, dados apresentados pelo Censo Escolar do MEC (2003) revelaram que, a ampla maioria dos professores brasileiros (69\%) que trabalha com crianças de quatro a seis anos, não possui nível superior, considerando-se, certamente, que essa qualificação seria um indicador de qualidade. Assim, além de se ter carência de instituições voltadas para o atendimento infantil, há uma notável falta de qualidade nesse atendimento, a qual pode ser traduzida, entre outras coisas, pelo grau de envolvimento das crianças nas atividades ofertadas pela instituição e pelo nível de empenho dos educadores, conforme salientam Pascal e Bertran (1999).

Vale apontar que há, infelizmente, uma grande distância entre o conhecimento produzido cientificamente acerca da educação de zero a seis anos e a prática efetiva nas instituições infantis brasileiras, a qual pode ser observada, por exemplo, pela precariedade de atividades realmente significativas, contextualizadas e adequadas ao pleno desenvolvimento da criança pequena, evidenciando a necessidade de uma formação contínua do educador. Sousa (2006) constatou num interessante estudo realizado em abrigos que, não raras vezes, a variável "gostar de crianças", independente da capacitação ou formação profissional, é a de maior peso na escolha profissional do educador. Por outro lado, pesquisas evidenciando a íntima relação existente entre o desenvolvimento do cérebro humano e a qualidade da estimulação ofertada na primeira infância (Shore, 2000), bem como o papel das brincadeiras infantis para o desenvolvimento dos hemisférios cerebrais (Antunha, 2000), não são disseminadas nas práticas educativas, como seria desejado.

Vygotsky (1989) foi um dos precursores ao assinalar a importância da mediação para a aprendizagem e o desenvolvimento mental da criança, considerando em termos do desenvolvimento real e o nível de desenvolvimento potencial, sendo a zona de desenvolvimento proximal, definida como:

“... distância entre o nível de desenvolvimento real, que se costuma determinar através da solução independente de problemas, e o nível de desenvolvimento potencial, determinado através da solução 
de problemas sob orientação de um adulto ou em colaboração com companheiros mais capazes" (p.97).

A partir da obra de Vygotsky, a qual se encontra devidamente registrada na edição brasileira do seu livro "A Formação Social da Mente" (1989), vários trabalhos, como os de Laevers, (1996) e Klein, (1996a) têm sido desenvolvidos com o propósito de enfatizar a importância da mediação ou "empenho" do educador no processo de aprendizagem do educando. Laevers (1996) define o empenho do educador como o modo como $o$ adulto lida com os conflitos, as regras e os problemas de comportamento. A presença ou ausência dos indicadores sensibilidade, que está relacionada a atenção e cuidado que o adulto demonstra ter para com os sentimentos e bem estar emocional da criança, a estimulação que está ligada ao modo como o adulto intervém no processo de aprendizagem e o conteúdo de tais intervenções e, a autonomia que implica no grau de liberdade que 0 adulto concede à criança para experimentar, emitir juízos, escolher atividades e expressar idéias e opiniões, é considerada. Por outro lado, a qualidade da interação entre adulto-criança, constitui-se a tônica do Programa de Intervenção Mediacional para um Educador mais Sensível (MISC), que se baseia na possibilidade de se aguçar a capacidade da criança pequena para aprender, com ênfase no planejamento, na avaliação de ações e no confronto com a realidade.

O Programa de Intervenção Mediacional para um Educador mais Sensível (MISC) é, segundo Klein e Hundeide (1992), a primeira tentativa para definir, avaliar e modificar variáveis específicas de comportamento dos adultos que se constituem em condições necessárias e suficientes, para uma adequada interação entre pais e filhos ou, ainda, entre educador e educando no seu sentido mais abrangente. Pesquisas realizadas em vários países (Klein, 1996a) mostram que tanto as crianças, quanto os adultos se beneficiam do Programa MISC, pois o mesmo enfatiza as potencialidades e as possibilidades dos participantes, de modo que possam atuar eficazmente como bons mediadores, ou seja, atuarem na zona de desenvolvimento proximal do mediado, fomentando o seu desenvolvimento.
O programa supracitado se baseia na teoria da modificabilidade cognitiva estrutural de Feuerstein (1980) - que ao rejeitar a idéia de que o ser humano ao nascer já é possuidor de uma estrutura cognitiva prédeterminada, introduz a possibilidade de mudança da mesma, a qual ocorre em virtude dos processos mediadores e da inter-atuação do indivíduo "(respondendo e atuando) com os estímulos que afetam a sua conduta cognitiva, afetiva, emocional e motivacional" (Silva, 2006, p: 4). Assim, o Programa MISC se fundamenta em cinco comportamentos básicos numa mediação de qualidade, denominados como focalização, expansão, afetividade, recompensa e regulação do comportamento, os quais possibilitam uma maior flexibilidade mental, além de uma predisposição para a aprendizagem (Klein 1996a; 1996b).

O primeiro critério mediacional definido como focalização inclui todas as tentativas do mediador para assegurar que a criança focalize a atenção em algo que está ao redor dela. Deve estar claro a indicação da intencionalidade do adulto para mediar e a reciprocidade da criança, a qual é expressa pelas suas respostas verbais ou não - verbais ao comportamento do adulto. A expansão está presente quando o "educador" tenta ampliar a compreensão da criança daquilo que está à sua frente, através da explicação, da comparação, adicionando novas experiências além das necessárias para o momento. A afetividade ou mediação do significado refere-se a toda a energia emocional utilizada pelo adulto durante a interação com a criança, levando a mesma a compreender o significado dos objetos, pessoas, relações e eventos ambientais. A recompensa é observada quando os adultos expressam satisfação com o comportamento das crianças e explicam o porquê de estarem satisfeitos, facilitando à mesma sentimentos de autocontrole, de capacidade e sucesso, além de ampliar a sua disponibilidade para explorar ativamente o novo. A regulação do comportamento é identificado quando o adulto ajuda a criança a planejar antes de agir, levandoa a se conscientizar da adequação do "pensar" antes de ação, de modo que possa planejar os passos do seu comportamento para atingir um objetivo. Atender aos cinco critérios citados implica em atingir uma mediação adequada 
Klein e Rye (2004) em um estudo desenvolvido com mães de tribos da Etiópia, onde os princípios básicos do Programa MISC foram implementados à cultura local, com vistas a uma melhora na qualidade de interações da díade adulto-criança e conseqüentemente, na promoção do potencial de aprendizagem das crianças, observaram que, mesmo após seis anos da intervenção, as mudanças significativas na qualidade de tais interações ainda persistiam, com efeitos positivos nas crianças no que respeita ao seu desenvolvimento cognitivo e socioemocional.

Os itens que deram início a escala ora tratada foram arrolados em trabalho anteriormente desenvolvido por Vectore (2003), que procurou identificar comportamentos mediacionais específicos, por meio da análise de vídeogravações de interações educadoracriança, em situações lúdicas. Vale acrescentar, que tais comportamentos estão relacionados com os pressupostos existentes no programa MISC, isto é, foram identificados a partir dos cinco critérios acima aludidos.

A teoria da modificabilidade cognitiva (Souza, Depresbiteris \& Machado, 2004) que embasa o Programa MISC tem demonstrado uma pertinente consistência na explicação dos fenômenos mediacionais, bem como de suas implicações, atestados por vários trabalhos produzidos em diferentes contextos internacionais (Odom \& Wolery, 2003; Klein \& Rye, 2004). Nesse sentido, o objetivo de presente estudo é apresentar evidências de validade para validar uma escala de avaliação de comportamentos de empenho observados na interação de educadores infantis com crianças pequenas de creche e educação infantil em situações lúdicas.

\section{Método}

\section{Elaboração dos Itens da escala e validação de conteúdo}

Como primeira etapa de construção da Escala de Avaliação da Mediação de Educadores Infantis, realizou-se um levantamento bibliográfico de conceitos ligados à mediação, bem como dos critérios mediacionais proposto na literatura (Klein, 1996a, 1996b) e arrolaram-se os comportamentos mediacionais identificados por Vectore (200I), num estudo implementado com educadoras infantis em situação de interação com crianças de zero a seis anos, oriundas de pré-escolas públicas e particulares da cidade de Uberlândia, em Minas Gerais. No estudo citado, após a identificação dos comportamentos mediacionais, procedeu-se à sua classificação, considerando os cinco critérios mediacionais, ou seja, a focalização, a expansão, a afetividade (mediação do significado), a recompensa e a regulação do comportamento.

A partir do estudo de Vectore (2003), procedeuse a elaboração de frases que representavam o comportamento mediacional, considerando os critérios mediacionais do Programa MISC, totalizando 58 itens, sendo II referentes à focalização ( $a$ educadora ensina as criança, demonstrando como fazer as atividades), 08 à expansão (a professora observa as crianças, suas brincadeiras e propõe novas formas de brincar); 13 à afetividade (a professora explica para as crianças o que significa perder e ganhar na brincadeira, enfatizando que não precisavam ficar tristes ao perderem um jogo), 14 à recompensa (a professora elogia uma criança, dizendo que ela fez a conta de cabeça e que é boa mesmo em matemática) e 12 à regulação do comportamento (a educadora adverte as crianças que estão perturbando a atividade, lembrando-lhes as de possíveis punições). Evitou-se o uso de frases que descrevessem aspectos subjetivos da interação educador - criança e assim, não diretamente observáveis.

\section{Análise de Concordância dos Itens}

A lista de itens composta pelos 58 comportamentos, foi submetida a cinco juízes, sendo quatro psicólogas, docentes, atuantes a mais de quinze anos na área de Psicologia Escolar e Educacional e uma estudante do curso de Psicologia que já conheciam o Programa MISC, cujo material foi trazido por Vectore, quando de sua participação no Advanced Research Training Seminar (ARTS), ocorrido no Canadá em 1996, organizado por Pnina Klein, com objetivo de 
conhecimento e divulgação do programa, nos países de origem dos pesquisadores previamente selecionados para tal. Assim, considera-se que todas estavam aptas a empreenderem tal tarefa. A elas foram apresentadas, além das definições dos cinco critérios mediacionais, o conjunto dos 58 itens, dispostos aleatoriamente, sendo solicitado que julgassem se um dado item representava, em termos conceituais, algum dos cinco critérios mediacionais. Os juízes avaliaram cada um dos itens, colocando nos parênteses que os sucediam, a letra correspondente ao conceito do critério mediacional que julgavam representar.

Com as respostas dos juízes, foi possível calcular a freqüência de indicação de cada frase constante na lista. Para cada um dos itens foi calculado o Índice de Concordância (IC) entre os juízes. Foram eliminados os itens com IC $<0,06$. Apesar de, segundo Pasquali (1997;1999), na construção de escalas, na análise dos itens e de sua validade de conteudo, estes devem apresentar $I C<0,08$, a falta de estudos sobre identificação de critérios mediacionais no Brasil (Klein, 2000), justificam tal critério.

Os resultados indicaram que dos 58 comportamentos mediacionais iniciais, 37 (64\%) obtiveram índice de concordância maior ou igual a $60 \%$ e 21 (36\%) obtiveram índice de concordância abaixo de $60 \%$. (Tabela I).

\section{Estudo para validação de conteúdo Participantes}

Participaram do estudo 315 educadores de escolas de Educação Infantil, que trabalham há 8 anos, em média, com idade de 16 a 59 anos. Dentre eles, $98 \%$ são mulheres, com grau de escolaridade variando do primeiro grau completo (1\%) a curso de pós-graduação (12\%), sendo a maioria casada (6I\%). É interessante ressaltar que muitos educadores estão cursando faculdade e há educadores infantis formados em comunicação social, direito, fonoaudiologia, história, matemática e serviço social, sendo que um educador fez mestrado. Em termos de localização por região, 31 I (98,7\%) atuam no Estado de Minas Gerais e 04 (I,3\%) no Estado de São Paulo.

\section{Instrumento}

\section{Escala de Avaliação da Mediação de Educadores Infantis}

Tem por objetivo a avaliação de comportamentos mediacionais, observados na interação de educadores com crianças pequenas (de 4 a 6 anos) em atividades lúdicas. Foi composta por 37 itens, englobando os critérios mediacionais denominados focalização (05 itens); expansão (05 itens); mediação do significado (05 itens); recompensa (I2 itens); regulação do comportamento ( 12 itens). As freqüências variaram de um (I) a quatro (4) pontos, sendo (I) o comportamento apontado nunca ocorre;(2) o comportamento apontado ocorre poucas vezes; (3) o comportamento apontado ocorre muitas vezes e (4) o comportamento apontado ocorre sempre.

\section{Procedimento}

Para a aplicação do instrumento foram recrutados oito alunos do curso de Psicologia da Universidade

Tabela I: Índice de Concordância na Avaliação Semântica dos Juízes e Itens Resultantes da Escala de Avaliação dos Comportamentos Mediacionais de Educadores.

\begin{tabular}{llll}
\hline Critérios Mediacionais & $\mathrm{N}^{\circ}$ itens iniciais & $\mathrm{N}^{\circ}$ itens selecionados & Porcentagem \\
\hline Focalização & 11 & 05 & $45 \%$ \\
Expansão & 08 & 05 & $63 \%$ \\
Mediação do Significado & 13 & 05 & $40 \%$ \\
Recompensa & 14 & 12 & $86 \%$ \\
Regulação Comportamento & 12 & 10 & $60 \%$ \\
\hline
\end{tabular}


Federal de Uberlândia, os quais foram devidamente treinados para a realização das observações em sala de aula, capacitando-os a atuarem como auxiliares de pesquisa na coleta de dados. Estes foram até escolas de Educação Infantil, a fim de explicarem o trabalho, bem como obterem a autorização da instituição, para que os educadores pudessem ser observados, em sala de aula. Nas escolas que permitiram as observações, foi deixado o termo de consentimento, para que os diretores ou coordenadores assinassem e carimbassem, conforme procedimento exigido pelo Comitê de Ética.

Os observadores ficaram de uma a duas aulas com cada educador, totalizando cerca de setenta e cinco minutos em média em cada sala de aula, a fim de observar os comportamentos descritos na escala piloto, anotando a freqüência que eles ocorriam.

\section{Resultados e Discussão}

A análise dos fatores principais pelo Método Oblimin, definindo-se como carga fatorial mínima 0,35, por item, apontou a existência de quatro agrupamentos consistentes de itens com eigenvalues superiores a I,9, explicando $36 \%$ da variância total (Tabela 2 ).

Os fatores identificados foram analisados semanticamente conforme conceitos propostos para cada critério do programa de treinamento MISC. As denominações dos fatores, o número de itens de cada um e os índices de precisão estão resumidos na Tabela 3.
Todos os fatores tiveram índices de precisão acima de 0,70 (entre 0,79 e 0,86) considerados satisfatórios (Pasquali, 1997), o que determinou a manutenção dos fatores 3 e 4 apesar da pouca representatividade quanto à explicação da variância dos itens na escala (5\%). Após essa análide, a Escala de Avaliação da Mediação de Educadores Infantis ficou constituída por quatro fatores representados por 23 itens com carga fatorial igual ou superior a 0,35.

A Tabela 4 apresenta os resultados referentes aos itens do Fator I-Interação dos educadores nas atividades lúdicas, com cargas fatoriais entre 0,57 e 0,84 e comunalidades entre 0,44 e 0,66 . Este fator congrega um conjunto de itens referentes às brincadeiras infantis. A mediação do educador pode ocorrer através da participação nas brincadeiras, no ensino de atividades lúdicas e de novos conteúdos, na explicação para as crianças a respeito de como brincar com um jogo específico e, finalmente pelo critério mediacional da regulação do comportamento durante o brincar.

Os sete itens do Fator 2, denominado Modos de transmissão de conteúdos, com cargas fatoriais entre 0,39 e 0,73 e comunalidades entre 0,26 e 0,60, referem-se aos modos de transmissão de conteúdos do educador para as crianças. É interessante observar que, numa mediação de qualidade, os mesmos ocorrem por meio da orientação das atividades junto aos pequenos, do esclarecimento dos significados, da utilização de exemplos concretos e do contínuo reforço do conteúdo estudado (Tabela 5).

Tabela 2: Eigenvalues, porcentagem de variância total e acumulada dos quatro principais componentes.

\begin{tabular}{llll}
\hline Fatores & Eigenvalues & \% variância total & \% variância acumulada \\
\hline 1 & 7,25 & 19,6 & 19,59 \\
2 & 2,29 & 6,2 & 25,79 \\
3 & 2,04 & 5,5 & 31,29 \\
4 & 1,91 & 5,2 & 36,49 \\
\hline
\end{tabular}


Tabela 3: Denominação, número de itens e índices de precisão dos quatro fatores.

\begin{tabular}{|c|c|c|c|}
\hline Fatores & Denominação & $\mathrm{N}^{\circ}$ de itens & $\begin{array}{c}\text { Precisão } \\
\text { (Alpha de Cronbach) }\end{array}$ \\
\hline 1 & $\begin{array}{c}\text { Interação dos } \\
\text { educadores nas } \\
\text { atividades lúdicas. }\end{array}$ & 06 & 0,86 \\
\hline 2 & $\begin{array}{l}\text { Modos de transmissão } \\
\text { de conteúdos para as } \\
\text { crianças. }\end{array}$ & 07 & 0,79 \\
\hline 3 & $\begin{array}{l}\text { Recompensa ofertada } \\
\text { às crianças. }\end{array}$ & 07 & 0,84 \\
\hline 4 & $\begin{array}{c}\text { Postura dos } \\
\text { educadores frente às } \\
\text { brincadeiras } \\
\text { envolvendo } \\
\text { competição. }\end{array}$ & 03 & 0,86 \\
\hline
\end{tabular}

Tabela 4: Carga fatorial (CF) descrição e comunalidade $\left(h^{2}\right)$ dos itens integrantes do Fator I - Interação dos educadores nas atividades lúdicas.

\begin{tabular}{lllll}
\hline Ordem & Item & CF & Descrição & $h^{2}$ \\
\hline 01 & 03 & 0,75 & $\begin{array}{l}\text { O educador participa da brincadeira das crianças e a } \\
\text { aproveita para ensinar alguns conteúdos (regras, cor. } \\
\text { tamanho etc). }\end{array}$ & 0,56 \\
02 & 06 & 0,84 & $\begin{array}{l}\text { O educador observa as crianças, suas b rincadeiras e propõe } \\
\text { novas formas de brincar. }\end{array}$ & 0,65 \\
03 & 09 & 0,57 & $\begin{array}{l}\text { O educador explora o jogo com as crianças. } \\
\text { O educador explica a brincadeira demonstrando através de }\end{array}$ & 0,66 \\
04 & 10 & 0,79 & $\begin{array}{l}\text { gestos. } \\
\text { O educador controla o comportamento das crianças nas } \\
\text { brincadeiras. }\end{array}$ & 0,52 \\
06 & 25 & 0,61 & $\begin{array}{l}\text { O educador observa e elogia a criatividade das crianças nas } \\
\text { brincadeiras. }\end{array}$ & 0,36 \\
& 35 & 0,43 & \\
\hline
\end{tabular}


Tabela 5: Carga fatorial (CF), descrição e comunalidade $\left(\mathrm{h}^{2}\right)$ dos itens integrantes do Fator 2 - Modos de transmissão de conteúdos.

\begin{tabular}{|c|c|c|c|c|}
\hline$\overline{\text { Ordem }}$ & Item & $\mathrm{CF}$ & Descrição & $\mathrm{h}^{2}$ \\
\hline$\overline{01}$ & 02 & 0,65 & $\begin{array}{l}\text { O educador orienta as atividades das crianças, passo - } \\
\text { a-passo. }\end{array}$ & 0,51 \\
\hline 02 & 05 & 0,39 & $\begin{array}{l}\text { O educador preocupa } \text {-se em esclarecer para as } \\
\text { crianças o significado dos acontecimentos. }\end{array}$ & 0,26 \\
\hline 03 & 14 & 0,61 & $\begin{array}{l}\text { O educador explica as normas de conduta na sala de } \\
\text { aula (disciplina e limites). }\end{array}$ & 0,39 \\
\hline 04 & 18 & 0,43 & $\begin{array}{l}\text { O educador preocupa -se em dar exemplos concretos, } \\
\text { para explicar os diferentes conteúdos trabalhados. }\end{array}$ & 0,34 \\
\hline 05 & 19 & 0,73 & $\begin{array}{l}\text { O educador enfatiza o significado das atividades } \\
\text { propostas, de modo que as crianças as compreendam. }\end{array}$ & 0,60 \\
\hline 06 & 24 & 0,43 & $\begin{array}{l}\text { O educador procura ampliar o conhecimento das } \\
\text { crianças, utilizando -se de expedientes que são para } \\
\text { elas prazerosos. }\end{array}$ & 0,41 \\
\hline 07 & 36 & 0,58 & $\begin{array}{l}\text { O educador aproveita qualquer atividade, para reforçar } \\
\text { o conteúdo estudado. }\end{array}$ & 0,38 \\
\hline
\end{tabular}

Tabela 6: Carga Fatorial (CF), descrição e comunalidade $\left(\mathrm{h}^{2}\right)$ dos itens integrantes do Fator 3 - Recompensa.

\begin{tabular}{|c|c|c|c|c|}
\hline Ordem & Item & $\overline{\mathrm{CF}}$ & Descrição & $\mathrm{h}^{2}$ \\
\hline 01 & 01 & 0,66 & O educador elogia as crianças. & 0,58 \\
\hline 02 & 12 & 0,58 & $\begin{array}{l}\text { O educador elogia as ações das crianças, explicando } \\
\text { o porquê do elogio. }\end{array}$ & 0,53 \\
\hline 03 & 13 & 0,79 & O educador elogia o trabalho das crianças. & 0,66 \\
\hline 04 & 15 & 0,50 & O educador incentiva as iniciativas infantis. & 0,46 \\
\hline 05 & 17 & 0,41 & $\begin{array}{l}\text { O educador preocupa } \quad \text {-se em desenvolver a } \\
\text { linguagem das crianças. }\end{array}$ & 0,31 \\
\hline 06 & 28 & 0,72 & $\begin{array}{l}\text { O educador elogia as produções das crianças, de um } \\
\text { modo geral. }\end{array}$ & 0,63 \\
\hline 07 & 33 & 0,79 & $\begin{array}{l}\text { O educador elogia as produções das crianças, } \\
\text { quando as mesmas solicitam a sua atenção. }\end{array}$ & 0,56 \\
\hline
\end{tabular}


Tabela 7: Carga fatorial (CF), descrição e comunalidade $\left(h^{2}\right)$ dos itens integrantes do Fator 4 - Brincadeiras Competitivas.

\begin{tabular}{lllll}
\hline Ordem & Item & CF & Descrição & $\mathrm{h}^{2}$ \\
\hline 01 & 08 &,- 69 & $\begin{array}{l}\text { O educador incentiva a participação da turma, } \\
\text { para o reconhecimento do vencedor. }\end{array}$ & 0,68 \\
02 & 11 &,- 67 & $\begin{array}{l}\text { O educador premia os vencedores em } \\
\text { brincadeiras que envolvem competição. }\end{array}$ & 0,58 \\
03 & 26 &,- 72 & $\begin{array}{l}\text { O educador reconhece e gratifica o vencedor das } \\
\text { brincadeiras. }\end{array}$ & 0,67 \\
\hline
\end{tabular}

O conjunto dos sete itens do Fator 3, denominado Recompensa, com cargas fatoriais entre 0,41 e 0,79 e comunalidades entre 0,31 e 0,66 , referem-se à recompensa que o educador oferece à criança, por meio de elogios e incentivos (Tabela 6).

Os três itens do Fator 4, denominado Brincadeiras Competitivas, com cargas fatoriais entre $-0,67$ e $-0,72$ e comunalidades entre 0,58 e 0,68 , referem-se à postura do educador frente às brincadeiras envolvendo competição, de modo que são freqüentes comportamentos de incentivo da turma para o reconhecimento e premiação dos vencedores (Tabela 7).

Seria esperado a partir da perspectiva teórica selecionada, que cada fator, obtido por meio da análise fatorial, agrupasse itens referentes aos critérios mediacionais - focalização, expansão, mediação do significado, recompensa e regulação do comportamento - contudo, isso não foi constatado. O que se obteve foram grupos de comportamentos mediacionais, formados por diferentes critérios mediacionais, exibidos durante as atividades de rotina, que são freqüentes em grande parte das instituições infantis brasileiras, ou seja, as atividades se distribuem entre brincadeiras livres e competitivas, transmissão de conteúdos específicos e recompensas. Pondera-se que tal fato possa ter ocorrido em virtude da dificuldade dos educadores pesquisados em utilizarem as situações de brincadeiras como estratégias de desenvolvimento infantil, não atuando, de fato, como parceiros efetivos junto às crianças, de modo a desafiá-las para novos conhecimentos durante as atividades lúdicas.
Embora todos os comportamentos avaliados partiram de um enquadre nacional, ou seja, foram observados em instituições infantis brasileiras, deve se ter claro que, transpor conceitos elaborados em um outro contexto cultural e socioeconômico diverso da realidade brasileira, evidencia a necessidade de uma gama variada de novos estudos para uma perfeita adequação.Vale a pena ressaltar que, no caso em questão, foram observados comportamentos durante um tipo específico de interação educador-criança, ocorrida em situação aparentemente lúdica, tratandose de algo inédito considerando as experiências listadas na literatura internacional com o programa (Odom, Hanson, Blackman \& Kaul, 2003), onde os comportamentos são observadas dentro de um contexto interacional amplo.

Nesse sentido, é interessante apontar que, Vectore e Silva (1999) em um estudo realizado com mães de crianças pequenas (até três anos) de baixa renda encontraram baixíssimas freqüências do critério mediacional "expansão", o qual está ligado a possibilidade do mediador buscar outras experiências que não as presente no momento, a fim de enriquecer a compreensão do mediado. Assim, se o mediador não dispõe de informações cognitivas para tal, certamente esse critério não estará tão disponível à díade mediador-mediado, o que justifica o treinamento no programa., o qual só é empreendido após a identificação do critério mediacional mais utilizado pelo mediador. A título de exemplo, no estudo ora descrito, se o treinamento fosse realizado, dever- 
se-ia ser iniciado pelo critério recompensa, evidenciado junto ao fator 3 .

\section{Considerações Finais}

A compreensão de que uma mediação adequada entre o educador e a criança pode otimizar o desenvolvimento e aprendizagem infantil, lança luz sobre a importância de se conhecer efetivamente como ocorre tal processo e, desse modo, implementar intervenções capazes de fomentar uma educação de qualidade para a infância brasileira. Assim, construir instrumentos de medida que possam ser utilizados em contextos infantis, permite um olhar mais acurado sobre a realidade institucional, capaz de evidenciar aspectos sutis, mas não menos importantes, no dia-a-dia do educador junto às suas crianças.

Nesse sentido, é interessante observar que o espaço e o tempo de brincar, a despeito de sua importância para o desenvolvimento humano, têm sido equivocadamente subtraídos nas instituições infantis brasileiras, por atividades de natureza mais escolástica e conteudista. Vale apontar que, muitas vezes, o brincar existe, porém ocorre de forma aleatória, descontextualizada, sem a devida participação ou interação mediacional do educador, que parece não considerar, conforme observa Oliveira (1999) ao tratar dos fundamentos da teoria vygotskyniana, que "o brinquedo cria uma zona de desenvolvimento proximal na criança. No brinquedo a criança comporta-se de forma mais avançada do que nas atividades da vida real e também aprende a separar objeto e significado" (p.67), ou seja, por meio do brincar, a criança tem a possibilidade de se tornar mais inteligente, enfim mais desenvolvida.

O presente estudo, embora tenha atingido seu objetivo de construir um instrumento de medida para a Avaliação da Mediação de Educadores Infantis, identificando evidências preliminares de validade e precisão, ainda requer investigações futuras. Há necessidade de novos estudos sobre a escala de modo que a mesma possa produzir dados, investigando outras regiões do país, tornando cada vez mais consistente a sua aplicação em território brasileiro.
Isto posto, pondera-se que o presente instrumento é passível de ser utilizado, por possuir características psicométricas, em diagnósticos iniciais que visem conhecer mediações adequadas do educador em sua interação com crianças pequenas, além de possibilitar atividades de pesquisa e de intervenção em contextos de educação infantil.

\section{Referências}

Antunha, E. (2000). Jogos sazonais: coadjuvantes do amadurecimento das funções cerebrais. Em V. B. Oliveira (Org.), O brincar e a criança do nascimento aos seis anos (pp. 33-56). Petrópolis, RJ: Vozes.

Feuerstein, R. (1980). Instrumental enrichment: Redevelopment of cognitive functions of retarded performers. New York: University Park Press.

Formosinho, J. O., \& Formosinho, J. (200I). Associação criança: um contexto de formação em contexto. Braga, Portugal: Livraria Minho.

Fundo das Nações Unidas para a Infância - UNICEF (2005). Relatório da situação mundial da infância e adolescência brasileiras. [On-line]. Disponível em: http:// www.unicef.org.br/ Acesso em: 28/I I/2005.

Gardner, H. (1999). Arte, mente e cérebro. Porto Alegre: Artes Médicas Sul.

Klein, P. S. (1996a). Early intervention: Cross-cultural experiences with a mendiational mpproach. New York: Garland Publishers.

Klein, P. S. (1996b). Early childhood education: Seventy-first yearbook of the National Society for the Study of Education. Chicago: University of Chicago Press.

Klein, P. S. (2000). A developmental mediation approach to early intervention: Mediational Intervention for Sensitizing Caregivers (MISC). Educational \& Child Psychology, I7(3), $|9-3|$.

Klein, P. S., \& Hundeide, K. (1992). Mediated learning experiences and at-risk children. Em L. R. Williams \& D. P. Fromberg, (Orgs.), Encyclopedia of Early Childhood Education (p. 24I). New York: Garland Publishers.

Klein, P. S., \& Rye, H. (2004). Interaction-oriented early intervention in Ethiopia: the MISC approach. Infants \& Young Children, 17(4), 340-354. 
Laevers, F. (1996). An exploration of the concept of involvement as an indicator for qulity in early childhood education. Dundee: Scottish Consultative Council on the Curriculum.

Malaguzzi, L. (1994). Your image of the child: where eaching begins. Child Care Information Exchange, 96, 52-61.

Ministério da Educação. (2003). Censo escolar 2003. Brasília: Autor.

Ministério da Educação. (2005). Resultados preliminares censo escolar de 2005 [On-line]. Disponível em: http:// www.inep.gov.br/ Acesso em: 28/I I/2005.

Odom, S. L., \& Wolery, M. (2003). A unified theory of practice in early intervention/early childhood special Education: Evidence-based practices. The Journal of Special Education, 37(3), 164-173.

Odom, S. L., Hanson, M. J., Blackman, J. A., \& Kaul, S. (2003). Early Intervention Practices Around the World. Washington, DC: International Society on Early Intervention (ISEI).

Oliveira, M. K. (1999). Vygotsky: aprendizado e desenvolvimento um processo sócio-histórico ( $4^{\mathrm{a}}$ ed). São Paulo: Scipione.

Oliveira-Formosinho, J. \& Formosinho, J. (200I). Associação criança: um contexto de formação em contexto. Braga, Portugal: Livraria Minho.

Pascal, C., \& Bertram, T. (1999). Desenvolvendo a Qualidade em Parcerias: nove estudos de caso. Porto, Portugal: Porto Editora.

Pasquali, L. (1997). Psicometria: teoria e aplicações. Brasília: Editora UnB.

Pasquali, L. (Org.). (1999). Instrumentos psicológicos: manual prático de elaboração. Brasília: LABPAM/IBAPP.

Sarmento, M. J. (2003). As culturas da infância nas encruzilhadas da $2^{\mathrm{a}}$ modernidade. Em M. J. Sarmento \& A. B. Cerisara (Orgs.), Crianças e miúdos. Perspectivas sóciopedagógicas da infância e educação. Porto: Asa.
Shore, R. (2000). Repensando o cérebro: novas visões sobre o desenvolvimento inicial do cérebro. Porto Alegre: Mercado Aberto.

Silva, M. C. (2006). Feuerstein e a teoria da modificabilidade cognitiva estrutural [On-line]. Disponível em: http:// www.psicologia.com. pt Acesso em: 26/06/06.

Sousa, A. R. R. (2006). Abrigar... brincar: um estudo sobre as vivências lúdicas entre educadoras e crianças de um abrigo. Dissertação de Mestrado, Instituto de Psicologia, Universidade Federal de Uberlândia, Minas Gerais.

Souza, A. M. M., Depresbiteris, L., \& Machado, O. T. M. (2004). A mediação como princípio educativo: as bases teóricas de Reuven Feuerstein. São Paulo: SENAC.

Vectore, C., \& Silva, C. E. (1999). Adaptação do Programa MISC - Mediational Intervention for Sensitizing Caregivers - numa população brasileira de baixa renda. Texto \& Contexto, 8(2), 445-448.

Vectore, C. (200I). Adaptação e possibilidades de utilização do Programa MISC - "Mediational Intervention for Sensitizing Caregivers" na formação continuada de Professores de Educação Infantil. Relatório de Pesquisa de PósDoutorado, Faculdade de Educação da Universidade de São Paulo, São Paulo.

Vectore, C. (2003). O brincar e a intervenção mediacional na formação continuada de professores de educação infantil. Psicologia USP, I4(3), |05-131.

Vectore, C., \& Silva, C. E. (2004). Contribuições da Psicologia para um atendimento de qualidade na infância. Resumo apresentado Sociedade Brasileira de Psicologia (Org.), XXXIV Reunião Anual de Psicologia. Ribeirão Preto: SBP.

Vygotsky, L. S. (1989). A formação social da mente ( $3^{\mathrm{a} e d .) . ~ S a ̃ o ~}$ Paulo: Martins Fontes. 


\section{Anexo A}

\section{Prezado(a) Colega}

Com o intuito de tê-lo(a) como juiz(a) do instrumento a ser elaborado sobre a mediação educador-criança, pedimos a sua gentileza, no sentido de responder à escala abaixo, considerando as seguintes instruções:

( I) Coloque no parênteses à frente de cada questão a letra $\mathbf{F}$ se você julgar que trata-se de focalização; a letra $\mathbf{E}$ se trata-se de expansão; $\mathbf{S}$ se tratar-se de mediação do significado; $\mathbf{R}$ se tratar-se de recompensa e C se tratar-se de regulação do comportamento.

\section{(2) Assim, entende-se por:}

Focalização $(\mathbf{F})$ : inclui todas as tentativas do mediador para assegurar que a criança focalize a atenção em algo que está ao redor dela. Deve estar claro a indicação da intencionalidade do adulto para mediar e a reciprocidade da criança, a qual é expressa através de suas respostas verbais ou não-verbais ao comportamento do adulto.

Expansão (E): está presente quando o "educador" tenta ampliar a compreensão da criança daquilo que está à sua frente, através da explicação, da comparação, adicionando novas experiências além das necessárias para o momento.

Mediação do significado (S): diz respeito ao empenho do adulto, o qual tenta ajudar a criança a compreender o significado dos objetos, pessoas, relações e eventos ambientais.

Recompensa $(\mathbf{R})$ : ocorre quando os adultos expressam satisfação com o comportamento das crianças e explicam o porquê de estarem satisfeitos, facilitando à criança sentimentos de autocontrole, de capacidade e sucesso, além de ampliar a sua disponibilidade para explorar ativamente o novo.

Regulação do comportamento $(\mathbf{C})$ : ocorre quando o adulto ajuda a criança a planejar antes de agir, levando-a a se conscientizar da possibilidade de "pensar" antes de agir, planejando os passos do seu comportamento para atingir um objetivo.

Desde já agradecemos a sua inestimável colaboração.

Prof $^{a}$. Dr ${ }^{\mathrm{a}}$ Celia Vectore

Vanessa Cristina Alvarenga

(Bolsista PIBIC/CNPq).

1) A educadora adverte as crianças que estão perturbando a atividade lembrando a elas de possíveis punições. ( )

2) A educadora vai de mesa em mesa distribuindo massinha e explicando: “Pode fazer uma árvore, uma florzinha...”. ( )

3) A educadora enfatiza a importância da participação de todos no jogo. ( )

4) A professora explica para as crianças situações inusitadas (ex: a menina entra na sala com uma roupa de bailarina e os meninos falam que a calcinha dela estava aparecendo). ( )

5) A educadora explica a importância de se comemorar o Natal. ( ) 
6) A professora pergunta pra criança se ao invés de beterraba, ela tinha visto ameixas na árvore, e ela concorda com a professora que explica que beterraba é uma hortaliça e que dá debaixo da terra. ( )

7) A educadora percebe que está perdendo a ordem na sala, então conversa com as crianças, acalmando-as. ( )

8) A educadora enfatiza o significado das atividades propostas, de modo que as crianças as compreendam. ( )

9) A educadora acalmava alguma criança quando ficava mais agitada, durante o jogo. ( )

10) A educadora dá atenção a todas as crianças. ( )

II) A educadora diz: "O corpo humano é formado de três partes: Batman (cabeça), Robin (tronco) e Batgirl (membros)". ( )

12) A educadora elogia o trabalho das crianças. ( )

13) Uma menina chora muito, abraça a professora e deita em seu colo, responde que a mãe dela esqueceu tudo em casa com a mochila dela. A professora pergunta o que é tudo. ( )

14) A educadora adverte as crianças que estão perturbando a atividade lembrando a elas que podem se machucar. ( )

15) A professora observa as crianças, suas brincadeiras e propõe novas formas de brincar. ( )

16) Às vezes, alguém chama a professora para mostrar o que está fazendo. Ela diz: “Que lindo” ou “Muito bem”. ( )

17) As crianças foram brincar de "cabra cega", a professora pediu para as crianças não gritarem muito, pois iria atrapalhar a brincadeira. ( )

18) A educadora incentiva as crianças a participarem da brincadeira. ( )

19) A educadora pede que todos aplaudam o vencedor. ( )

20) A professora explica o porque de alterações na rotina (feriado). ( )

21) A educadora ensina as criança, demonstrando como fazer as atividades (amassar as bolinhas, girando devagar a massinha entre as mãos). ( )

22) A professora observou e elogiou a criatividade das meninas na brincadeira. ( )

23) A professora aproveita atividades lúdicas para reforçar o conteúdo estudado (ex: leitura das palavras escritas na caixa do jogo). ( )

24) Uma das meninas pediu para a educadora contar para outra coleguinha, como era a cadeia e que lá só tinha arroz e que não se comia. Aí, uma outra criança acrescentou que era arroz com feijão. A educadora completou dizendo que a cadeia era muito ruim. ( )

25) A educadora explica as regras da brincadeira na linguagem das crianças. ( )

26) A educadora pede a criança para explicar o que estava fazendo com a sucata. ( )

27) A educadora disse que quando precisassem dela, que levantassem o dedo. ( )

28) A educadora conta uma história com um livro e cuida para que todas as crianças percebam e acompanhem as narrativas pelas gravuras. ( )

29) A professora elogia uma criança, dizendo que ela fez a conta de cabeça e que é boa mesmo em matemática. ( )

30) A educadora aplaude vencedor e perdedor, não exalta nenhuma destas posições. ( )

31) Uma criança pegou material de sucata e começou a montar várias estruturas, quando a professora viu o que ela estava fazendo se aproximou elogiando. ( )

32) A educadora distribuiu uma caixa de brinquedos, orientando que ao término da brincadeira devem guardar tudo novamente. ( )

33) A professora levantou o vencedor da brincadeira. ( )

34) A educadora explica a brincadeira demonstrando através de gestos. ( )

35) Os ganhadores do bingo tiveram como prêmio balóes. ( )

36) A educadora explica as normas de conduta na sala de aula (disciplina e limites). ( )

37) A educadora chama a atenção da criança, através do grito. ( )

38) A professora explica para as crianças o que significa perder e ganhar na brincadeira, enfatizando que não precisavam ficar tristes ao perderem um jogo. ( )

39) Um menino perguntou a educadora, se na cadeia a comida era gelada. Ela respondeu que tudo de ruim que eles pudessem pensar, tinha na cadeia, tudo era ruim. ( ) 
40) Durante a atividade a educadora chama a atenção de alguma criança, pedindo que se retire e explica as outras crianças porque fizera isto. "Ele não estava deixando a tia dar a aula dela". ( )

4I) A educadora preocupa-se em ensinar a todas as crianças, através da proximidade corporal com as crianças. ( )

42) A educadora elogia as ações das crianças. ( )

43) A educadora explica, através da fala, como é a brincadeira. ( )

44) A educadora compreende e respeita as dificuldades de cada criança. ( )

45) Uma criança fala que vai ceder sua vez para outra porque ele não tinha pintado no dia anterior e a professora elogia o comportamento e a atitude da criança. ( )

46) A educadora participa da brincadeira, chamando a atenção das crianças para alguns aspectos do jogo (regras, cor, tamanho etc). ( )

47) A educadora incentiva as crianças que saem da competição, a torcerem pelos que ainda estavam competindo. ( )

48) A educadora incentiva a participação de todos no jogo. ( )

49) Uma criança com a canetinha laranja na mão, pergunta à professora o que é laranja, o que significa a cor laranja e ela explica que o laranja é estimulante do apetite, que dá vontade de comer, por isso, que o Mc’Donalds é laranja e amarelo". ( )

50) A educadora elogia as produções das crianças. ( )

51) A educadora pega o monte de peças e fala o nome de cada peça em voz alta. ( )

52) A educadora não permite que as crianças utilizem objetos pertencentes a outras pessoas. ( )

53) A educadora só dá atenção às crianças quando é para chamar a atenção. ( )

54) A educadora distribui vários brinquedos e, enfatiza para as crianças as normas a serem observadas. ( )

55) A educadora explica o que mais as crianças podem fazer no jogo. ( )

56) A educadora se aproxima de algumas crianças e propõe uma atividade, como por exemplo, pular corda, e explica-lhes como fazer enquanto bate a corda. ( )

57) A educadora ao chamar a atenção de uma das crianças que está gritando ela também grita: "Não grita não!". ( )

58) A educadora brincava um pouco com cada criança. ( ) 


\section{Anexo B}

\section{Escala de comportamentos mediacionais de educadores infantis}

\section{Instruções:}

A presente escala foi elaborada com o objetivo de conhecer os comportamentos mediacionais de educadores infantis. Para cada questão formulada, pedimos que o observador, dê a freqüência do comportamento apontado, considerando:

I O comportamento apontado NUNCA ocorre

2 O comportamento apontado ocorre POUCAS VEZES

3 O comportamento apontado ocorre MUITAS VEZES

4 O comportamento apontado SEMPRE

\section{Comportamentos mediacionais Freqüência}

I) $\mathrm{O}(\mathrm{A})$ educador(a) elogia as crianças. (I) (2) (3) (4)

2) $O(A)$ educador(a) orienta as atividades das crianças passo-a-passo. (I) (2) (3) (4)

3) $\mathrm{O}(\mathrm{A})$ educador(a) participa da brincadeira das crianças e a aproveita para ensinar alguns conteúdos (regras, cor, tamanho, etc).

(I) (2) (3) (4)

4) $\mathrm{O}(\mathrm{A})$ educador(a) preocupa-se em esclarecer para as crianças o significado dos acontecimentos. (I) (2) (3) (4)

5) $\mathrm{O}(\mathrm{A})$ educador(a) observa as crianças, suas brincadeiras e propõe novas formas de brincar. (I) (2) (3) (4)

6) $O(A)$ educador(a) incentiva a participação da turma, para o reconhecimento do vencedor. (I) (2) (3) (4)

7) $O(A)$ educador(a) explora o jogo com as crianças. (I) (2) (3) (4)

8) $O(A)$ educador(a) explica a brincadeira demonstrando através de gestos. (I) (2) (3) (4)

9) $O(A)$ educador(a) premia os vencedores nas brincadeiras que envolvem competição. (I) (2) (3) (4)

10) $O(A)$ educador(a) elogia as ações das crianças, explicando o porquê do elogio. (I) (2) (3) (4)

II) $\mathrm{O}$ (A) educador(a) elogia o trabalho das crianças. (I) (2) (3) (4)

12) $\mathrm{O}(\mathrm{A})$ educador(a) explica as normas de conduta na sala de aula (disciplina e limites). (I) (2) (3) (4)

13) $\mathrm{O}(\mathrm{A})$ educador(a) incentiva as iniciativas infantis. (I) (2) (3) (4)

14) $\mathrm{O}(\mathrm{A})$ educador(a) preocupa-se em desenvolver a linguagem das crianças. (I) (2) (3) (4)

15) O(A) educador(a) preocupa-se em dar exemplos concretos, para explicar os diferentes conteúdos trabalhados. (I) (2) (3) (4)

16) $\mathrm{O}$ (A) educador(a) enfatiza o significado das atividades propostas, de modo que as crianças as compreendam. (I) (2) (3) (4)

17) $\mathrm{O}(\mathrm{A})$ educador(a) procura ampliar o conhecimento das crianças, utilizando-se de expedientes que são para elas prazerosos.

(I) (2) (3) (4)

18) $\mathrm{O}(\mathrm{A})$ educador(a) controla o comportamento das crianças nas brincadeiras. (I) (2) (3) (4)

19) $O(A)$ educador(a) reconhece e gratifica o vencedor das brincadeiras. (I) (2) (3) (4)

20) $O(A)$ educador(a) elogia as produções das crianças, de um modo geral. (I) (2) (3) (4)

21) O(A) educador(a) elogia as produções das crianças, quando as mesmas solicitam a sua atenção. (I) (2) (3) (4)

22) O educador(a) observa e elogia a criatividade das crianças nas brincadeiras. (I) (2) (3) (4)

23) $\mathrm{O}(\mathrm{A})$ educador(a) aproveita qualquer atividade para reforçar o conteúdo estudado. (I) (2) (3) (4) 


\section{DADOS COMPLEMENTARES}

I. Sexo: $M() \quad F()$

2. Idade: anos

3. Tempo na função de Educador(a)/Professor(a):

4. Estado Civil:
( ) solteira(o)
( ) casada(o)
( ) outros

5. Grau de instrução:

Recebido em: 19/12/2005

Revisado em: 26/03/2006

Aprovado em: 30/05/2006

Sobre os autores:

Celia Vectore (vectore@ufu.br) é Professora Adjunta da Universidade Federal de Uberlândia.

Vanessa Cristina Alvarenga (vanessacalvarenga@yahoo.com.br) é Bolsista do programa de Iniciação Científica, CNPq/UFU.

Sinésio Gomide Júnior (sinesiojunior@netsite.com.br) é Professor Adjunto da Universidade Federal de Uberlândia.

Endereço para correspondência:

Instituto de Psicologia, Universidade Federal de Uberlândia

Av. Pará, 1720.

38405-320 - Uberlândia, MG, 